THE ACTION OF CARBON DI-OXIDE ON THE RESPIRATION OF THE GOLD-FISH

By W. A. OSBORNE and EDITH MUNTZ.

From the Physiological Laboratory, University of Melbourne.

(Received Fuly 9th, 1906)

Whilst the action of carbon di-oxide on bioplasm generally is that of a narcotic poison, towards certain nerve cells and particularly those governing respiratory movements in the mammal, it behaves as an irritant. But even with these nerve cells, if the tension of the gas is high enough and its administration continued for a sufficiently long time, a condition of narcosis will finally supervene.

In man, according to Haldane and Priestley, ${ }^{1}$ the cells of the respiratory centre are exquisitely sensitive to any increase in the $\mathrm{CO}_{2}$ tension of the arterial blood with which they are supplied, an increase of $0.2 \%$ of an atmosphere causing a doubling of the lung ventilation. According to these investigators the regulation of the extent of pulmonary ventilation is carried out solely by the stimulating action of carbon di-oxide on the cells of the medullary centre.

The following research was undertaken to find out if possible whether alterations in the $\mathrm{CO}_{2}$ tensions of water were followed by changes in the respiration of fishes and whether any such regulatory mechanism as has been described above could be found in these animals.

\title{
Methods
}

Our investigations were confined to gold fish, as we could obtain them readily and in sufficient number. We hope to continue the research with other fresh-water teleosteans but the great difficulty

I. F. Physiol., Vol. XXXII, 225, 1905. 
we have experienced here in obtaining live unwounded specimens has hitherto prevented us from making the extensive series of observations which we had originally planned.

In order to obtain water containing carbon di-oxide at a definite tension two large flasks containing tap water were boiled half an hour and then placed in cold running water and allowed to cool overnight to room temperature. In the one case $\mathrm{CO}_{2}$-free air, and in the other case pure $\mathrm{CO}_{2}$ was bubbled through the water whilst cooling and as long as the experiments were in progress. Since the pressure of $\mathrm{CO}_{2}$ in one flask was an atmosphere and in another zero and as the water was from the same source, had been boiled for the same time and had the same temperature in each, it will be obvious that in any mixture of the two the $\mathrm{CO}_{2}$ tension will be the same percentage of an atmosphere as the volume percentage of the $\mathrm{CO}_{2}$-saturated water. The mixtures were rapidly made in a large Erlenmeyer flask placed close to the fish tank and the fish transferred from the latter as promptly and as quickly as possible. In some cases the same fish was allowed to remain in the Erlenmeyer whilst continuous additions of the $\mathrm{CO}_{2}$ water were made. It was found, however, that habituation to the dissolved gas was acquired and the same fish could not be used for experiments again on that day. With the lower tensions of $\mathrm{CO}_{2}$ ( $4 \%$ and less) the same fish could be used again after spending an hour in fresh running water.

In a few experiments a mixture of $\mathrm{CO}_{2}$ and air (or air plus oxygen) was made in a gasometer and the mixture bubbled for half an hour through water which was continuously shaken. Analyses of the mixture were made from time to time but it was found that though precautions were taken to have the water of the gasometer with approximately the same tension of $\mathrm{CO}_{2}$ as the contained air, a slight fall in the $\mathrm{CO}_{2}$ percentage of the latter was always found.

As the barometer remained very close to $760 \mathrm{~mm}$. whilst our experiments were being conducted no allowance for this factor was thought necessary in expressing the tensions of $\mathrm{CO}_{2}$ in terms of atmospheric percentages. 
IrRitant Action of $\mathrm{CO}_{2}$

When a gold-fish was placed in water saturated with $\mathrm{CO}_{2}$ and at the same temperature as the tank water, it swam violently about and refused absolutely to respire. Soon narcotic symptoms appeared and the fish eventually lay on its side at the bottom of the vessel. We have often observed a very slight movement of the opercula at this stage but none of the mouth. This refusal to breathe is obviously due to the irritating action of the $\mathrm{CO}_{2}$ on the mouth and gills and is comparable with closure of the glottis in mammals. With lesser tensions the fish after a preliminary refusal would subsequently commence to respire in a shallow way. The exact limit of respirability we could not determine, for, generally speaking, the higher the $\mathrm{CO}_{2}$ tension the longer was the pause and, as mentioned above, even in water fully saturated with the gas, faint respiratory movements of the opercula could often be observed. In one experiment where the water had been shaken with air containing $27.6 \% \mathrm{CO}_{2}$ and $59.3 \% \mathrm{O}_{2}$, respiration commenced abruptly after the lapse of two minutes. A similar pause was obtained when water was used which had been shaken with air containing $45.7 \% \mathrm{CO}_{2}$ and $44.7 \% \mathrm{O}_{2}$. A number of observations were made on this point and it was found that this respiratory pause could be detected with much lower percentages of $\mathrm{CO}_{2}$. The lowest in which it was observable was $\mathrm{I} \cdot 7 \% \mathrm{CO}_{2}$, obtained by the mixing method. With percentage saturations of $\mathrm{CO}_{2}$ lower than this we could not detect the slightest action on the respiratory movements. With higher tensions of $\mathrm{CO}_{2}$, though we never observed any indications of hyperpnoea, we noted that the respiration was remarkably regular and was altogether free from those voluntary pauses followed by deep gulps in which the normal gold-fish frequently indulges.

\section{Surface Breathing}

It was noted by Duncan and Hoppe-Seyler ${ }^{\mathrm{I}}$ that when the carp was placed in water with a very low oxygen tension the fish rose and respired the water as close to the actual surface as possible. This

I. Zeit. $f$. physiol. Chemie, Vol. XVII, 165, 1893. 
was observed with tinca vulgaris when the oxygen tension was $1 \cdot 84$, 0.78 and $0.38 \%$ of an atmosphere. The cobitis fossilis under similar circumstances rose to the surface and swallowed air. The trout apparently never resorted to this manoeuvre but when subjected to low tensions of oxygen flung itself wildly about, even jumped into the air and showed marked hyperpnoea. This effect of low oxygen tension we have also observed with the gold fish but we believe that the frequent rising of this fish to the surface in order to respire the upper layers, an action which is always seen when the water in which the fish is kept is not renewed sufficiently often, is due to another cause, namely, a rise in the tension of $\mathrm{CO}_{2}$. We have noticed this phenomenon when the $\mathrm{CO}_{2}$ tension of the water in which the fish was swimming was raised by a single addition of $\mathrm{CO}_{2}$ water from

$$
\begin{aligned}
& \text { zero to } 3.2 \% \text { atmosphere } \\
& \text { zero to } 10.7 \% \text { atmosphere } \\
& \text { zero to } 15 \% \text { atmosphere } \\
& 3.2 \% \text { to } 6 \% \text { atmosphere }
\end{aligned}
$$

A fresh investigation was then carried out in which different specimens of the gold-fish were used and in which the $\mathrm{CO}_{2}$ tension was raised from zero by small increments. To $3^{\frac{1}{2}}$ litres of $\mathrm{CO}_{2}$-free water small amounts of water (20 to 50 c.cs.) saturated with $\mathrm{CO}_{2}$ were added and a couple of minutes allowed for observation. A slight error in calculating the tension was caused by the presence of the fish which, of course, was constantly excreting $\mathrm{CO}_{2}$, but the comparatively large volume of the water and the low metabolism of

\begin{tabular}{|c|c|c|c|c|c|}
\hline Experiment & \multicolumn{2}{|c|}{ I surface } & hin & curr & $4 \% \quad \mathrm{CO}_{2}$ \\
\hline Experiment & II & , & " & , & $4 \% \mathrm{CO}_{2}$ \\
\hline Experiment & III & ", & ", & $"$ & $3.8 \% \mathrm{CO}_{2}$ \\
\hline Experiment & IV & " & "’ & ", & $4 \% \quad \mathrm{CO}_{2}$ \\
\hline Experiment & V & " & " & $"$ & $3.2 \% \mathrm{CO}_{2}$ \\
\hline Experiment & VI & , & ״ & , & $3.3 \% \mathrm{c}$ \\
\hline
\end{tabular}
the fish must have made this error a very small one. The Erlenmeyer flask gave so small a surface that $\mathrm{CO}_{2}$ loss during the experiment may also be neglected. 
A very interesting feature of this reaction to $\mathrm{CO}_{2}$ was the fact that on raising the tension still higher the fish abandoned surface breathing but sometimes resumed it when the tension had reached such figures as $13.9 \%, 14 \%, 15 \%$ or still higher percentages. There seems then, for the gold fish at least, a critical pressure of $\mathrm{CO}_{2}$ which will induce surface breathing and which, according to our experiments, lies between 3.2 and $4 \%$ of an atmosphere. Evidence for a second and higher critical point was not so uniform and conclusive.

That this rise to the surface was due to reflex action or instinct and not because the fish consciously swam in the direction of lessened $\mathrm{CO}_{2}$ pressure was shown by the speed of the rise and by the fact that it occurred in some test experiments when the atmosphere above the water contains $\mathrm{CO}_{2}$ at the same pressure as the water. That it was not due in these cases to oxygen deficiency we were able to disprove completely, for the reaction occurred when the fish was placed in water which had been shaken with air containing not only $\mathrm{CO}_{2}$ but high percentages of oxygen $(447 \%, 59.3 \%$, $63 \cdot 9 \%, 66 \cdot 3 \%)$.

The teleological significance of this response to $\mathrm{CO}_{2}$ is obvious. If the $\mathrm{CO}_{2}$ tension of the water be raised, either by the fish itself, if the amount and surface of the water be small, or by the evolution of $\mathrm{CO}_{2}$ from decomposing organic matter, the fish can still obtain water to respire with a low $\mathrm{CO}_{2}$ tension by means of this simple artifice.

\section{Narcotic Action of $\mathrm{CO}_{2}$}

At what pressure in the water carbon di-oxide begins to exercise a narcotic influence we could not determine owing to the irregular movements of the fish; but with tensions above $10 \%$ of an atmosphere the narcosis was marked. At first the fish lay at the bottom of the vessel respiring very regularly but refusing to swim about, though it could still do this in a normal manner if an attempt were made to catch it with the hand. Another sign of narcosis which we found to precede loss of equilibration was the loss of the 
head-to-stream reflex. If the water in the vessel were made to rotate in a mass about a vertical axis in the centre, the normal fish at once placed itself in a direction facing the current and by means of swimming movements maintained its position relative to the wall of the vessel and objects visible outside. But the fish poisoned by $\mathrm{CO}_{2}$ drifted with the current and with the long axis of its body at any angle to the direction of drift. A sign of more advanced narcosis was the loss of equilibration which was shown by the fish being no longer able to keep its dorsum uppermost. The body at first swayed from one side to another then got a permanent list to one side and finally heeled over completely. Recovery could always be rapidly effected if the fish were placed in fresh running water.

\section{Summary}

I. Tensions of $\mathrm{CO}_{2}$ greater than $\mathrm{I}^{\circ} 7 \%$ of an atmosphere produce in the gold-fish temporary inhibition of respiration comparable with the closure of the glottis in mammals.

2. Surface breathing can be produced in the gold-fish not only by oxygen deficiency (confirmatory of Duncan and HoppeSeyler) but also by $\mathrm{CO}_{2}$ at a tension which in our experiments varied between 3.2 and $4 \%$ of an atmosphere.

3. The sequence of narcotic manifestations in the gold-fish produced by $\mathrm{CO}_{2}$, is

I. Cessation of voluntary movement except when irritated.

2. Loss of head-to-stream reflex.

3. Loss of equilibration.

4. No action of $\mathrm{CO}_{2}$ on the respiratory centres comparable with that present in man could be discovered in the gold-fish. 